\title{
KETERBAGIAN TAK HINGGA SEBARAN RIEMANN ZETA
}

\author{
DONA ARIANI \\ Program Studi Matematika, \\ Fakultas Matematika dan Ilmu Pengetahuan Alam, Universitas Andalas, \\ Kampus UNAND Limau Manis Padang, Indonesia. \\ dona.ariani2219@yahoo.co.id
}

\begin{abstract}
Abstrak. Keterbagian tak hingga suatu sebaran dapat ditentukan dengan peubah acak, fungsi sebaran dan fungsi karakteristik. Suatu fungsi sebaran $F$ dengan fungsi karakteristik $\varphi(t)$ dikatakan terbagi tak hingga jika untuk setiap bilangan bulat positif $n$ terdapat fungsi karakteristik $\varphi_{n}(t)$ sedemikian sehingga $\varphi(t)=\left[\varphi_{n}(t)\right]^{n}$. Salah satu sebaran terbagi tak hingga adalah sebaran Riemann Zeta. Sebaran Riemann Zeta adalah sebaran yang berasal dari fungsi Riemann Zeta yang memuat peubah bilangan kompleks yaitu $\zeta(s)=\sum_{n=1}^{\infty} \frac{1}{n^{s}}$ dengan $s=\sigma+i t$.
\end{abstract}

Kata Kunci: Fungsi karakteristik, fungsi Riemann Zeta, sebaran terbagi tak hingga, sebaran Riemann Zeta

\section{Pendahuluan}

Peubah acak $X$ dikatakan terbagi menjadi $n$ jika terdapat peubah-peubah acak yang identik dan saling bebas $X_{1}, X_{2}, \cdots, X_{n}$ sedemikian sehingga $X=X_{1}+X_{2}+$ $\cdots+X_{n}$. Keterbagian tak hingga juga dapat dilihat berdasarkan fungsi sebaran dan fungsi karakteristik. Suatu fungsi sebaran $F$ dikatakan terbagi tak hingga jika untuk setiap bilangan bulat positif $n$ terdapat suatu fungsi sebaran $F_{n}$ sedemikian sehingga $F$ adalah konvolusi $n$ kali dari $F_{n}$ dengan dirinya sendiri, yaitu $F=$ $F_{n} * F_{n} * \cdots * F_{n}$ (sebanyak $n$ kali) [1]. Suatu fungsi sebaran $F$ dengan fungsi karakteristik $\varphi(t)$ adalah terbagi tak hingga jika untuk setiap bilangan bulat positif $n$ terdapat fungsi karakteristik $\varphi_{n}(t)$ sedemikian sehingga $\varphi(t)=\left[\varphi_{n}(t)\right]^{n}[2]$.

Salah satu sebaran yang menarik untuk ditentukan keterbagian tak hingganya adalah sebaran Riemann Zeta. Sebaran Riemann Zeta dapat dikonstruksi melalui fungsi Riemann Zeta. Fungsi Riemann Zeta yang dilambangkan dengan $\zeta(s)$ merupakan suatu fungsi dengan peubah bilangan kompleks $s$. Fungsi Riemann Zeta didefinisikan sebagai $[4,7]$ :

$$
\zeta(s)=\sum_{n=1}^{\infty} \frac{1}{n^{s}} \quad ; s=\sigma+i t, \sigma>1, t \in R .
$$

Dari fungsi Riemann Zeta tersebut dapat diperoleh sebaran Riemann Zeta. Misalkan didefinisikan $X=-\log n$ sebagai peubah acak untuk sebaran Riemann Zeta, 
maka didefinisikan fungsi kepekatan peluang dari Riemann Zeta sebagai berikut [3].

$$
f(-\log n)=\frac{1}{\zeta(\sigma) n^{\sigma}} \quad ; \sigma>1 . \quad[3]
$$

\section{Terminologi Fungsi Karakteristik dan Keterbagian Tak Hingga}

Fungsi karakteristik adalah salah satu jenis transformasi yang sering digunakan dalam ilmu Statistika. Pada bagian ini akan diberikan definisi dan sifat-sifat fungsi karakteristik serta keterbagian tak hingganya.

Definisi 2.1. [6] Jika $X$ suatu peubah acak dengan fungsi kepekatan peluang (fkp) $f(x)$ dan fungsi sebaran kumulatif $F(x)$, maka fungsi karakteristik $\varphi_{X}(t)$ dari peubah acak $X$ didefinisikan sebagai berikut

$$
\varphi_{X}(t)=E\left[e^{i t X}\right],
$$

dimana $e^{i t X}=\cos (t X)+i \sin (t X)$, dan $i$ adalah unit imajiner.

Proposisi 2.2. [6] Misalkan $\varphi_{X}(t)$ adalah fungsi karakteristik dari peubah acak $X$, maka

(1) $\varphi_{X}(0)=1$.

(2) $\varphi_{X}(t)$ ada untuk sebarang sebaran.

(3) Fungsi karakteristik dari $-X$ adalah sekawan dari fungsi karakteristik $\varphi_{X}(t)$ ditulis $\overline{\varphi_{X}(t)}$.

(4) $\varphi_{X}(t)$ adalah kontinu seragam.

(5) Fungsi karakteristik dari $a+b X$ adalah $e^{i t a} \varphi_{X}(b t)$.

(6) Fungsi karakteristik dari peubah acak $X$ bernilai riil jika dan hanya jika peubah acak $X$ mempunyai sebaran yang simetrik terhadap ordinat $x=0$ yaitu $P(X>$ $x)=P(X<-x)$ untuk $x=0$.

Ide dasar tentang sebaran terbagi tak hingga adalah keterbagian peubah acak $X$ menjadi peubah-peubah acak yang saling bebas dengan sebaran yang sama. Peubah acak $X$ dikatakan terbagi menjadi $n$ jika terdapat peubah-peubah acak yang identik dan saling bebas $X_{1}, X_{2}, \cdots, X_{n}$ sedemikian sehingga $X=X_{1}+$ $X_{2}+\cdots+X_{n}$. Selain dengan menggunakan peubah acak, keterbagian tak hingga dapat ditentukan dengan menggunakan fungsi karakteristik. Suatu fungsi sebaran $F$ dengan fungsi karakteristik $\varphi(t)$ adalah terbagi tak hingga jika untuk setiap bilangan bulat positif $n$ terdapat fungsi karakteristik $\varphi_{n}(t)$ sedemikian sehingga $\varphi(t)=\left[\varphi_{n}(t)\right]^{n}$ untuk setiap $t$.

Teorema 2.3. [8] Misal $\left\{Y, X_{1}, X_{2}, \cdots\right\}$ adalah peubah acak yang saling bebas dimana distribusi dari $Y$ adalah Poisson dengan nilai harapan $\mu$ dan $\left\{X_{n}\right\}$ menyebar identik dengan fungsi karakteristik $\varphi(t)$. Misal $Z=X_{1}+X_{2}+\cdots+X_{Y}$, maka fungsi karakteristik $Z$ terbagi tak hingga dengan fungsi karakteristiknya adalah

$$
\varphi_{Z}(t)=\exp (\mu(\varphi(t)-1)) .
$$


Bukti. Misal $Z=X_{1}+X_{2}+\cdots+X_{Y}$. Akan dibuktikan bahwa $\varphi_{Z}(t)=$ $\exp (\mu(\varphi(t)-1))$, dengan $Y \sim P O I(\mu)$ dan $X_{i}$ menyebar secara identik dengan fungsi karakteristik $\varphi(t)$. Perhatikan bahwa

$$
\begin{aligned}
\varphi_{Z}(t) & =E\left[e^{i t Z}\right] \\
& =E\left[e^{i t\left(X_{1}+X_{2}+\cdots+X_{Y}\right)}\right] \\
& =\sum_{n=0}^{\infty} E\left[I_{[Y=n]} e^{i t\left(X_{1}+X_{2}+\cdots+X_{Y}\right)}\right]
\end{aligned}
$$

Karena $I_{[Y=n]}$ dan $e^{i t\left(X_{1}+X_{2}+\cdots+X_{Y}\right)}$ saling bebas, maka

$$
\begin{aligned}
\varphi_{Z}(t) & =\sum_{n=0}^{\infty} E\left(\exp \left(i t\left(X_{1}+X_{2}+\cdots+X_{n}\right)\right)\right) P(Y=n) \\
& =\sum_{n=0}^{\infty} \frac{\varphi^{n}(t) e^{-\mu} \mu^{n}}{n !} \\
& =e^{-\mu} \sum_{n=0}^{\infty} \frac{\varphi^{n}(t) \mu^{n}}{n !} \\
& =e^{-\mu} \sum_{n=0}^{\infty} \frac{(\varphi(t) \mu)^{n}}{n !} .
\end{aligned}
$$

Berdasarkan Deret Taylor, $\sum_{n=0}^{\infty} \frac{(\varphi(t) \mu)^{n}}{n !}=e^{\varphi(t) \mu}$, sehingga diperoleh

$$
\begin{aligned}
\varphi_{Z}(t) & =e^{-\mu} e^{\varphi(t) \mu} \\
& =e^{\varphi(t) \mu-\mu} \\
& =e^{\mu(\varphi(t)-1)} \\
& =\exp (\mu(\varphi(t)-1)) .
\end{aligned}
$$

Selanjutnya akan ditunjukkan bahwa $\varphi_{Z}(t)$ adalah fungsi karakteristik dari sebaran terbagi tak hingga yaitu dengan memperlihatkan bahwa $\varphi_{Z}(t)=\left[\varphi_{n}(t)\right]^{n}$. Perhatikan bahwa

$$
\begin{aligned}
\varphi_{Z}(t) & =\exp (\mu(\varphi(t)-1)) \\
& =\exp \left(\frac{\mu}{n}(\varphi(t)-1)\right) n \\
& =\left(\exp \left(\frac{\mu}{n} \varphi(t)-1\right)\right)^{n} .
\end{aligned}
$$

Dengan mengambil $\varphi_{n}(t)=\left(\exp \left(\frac{\mu}{n} \varphi(t)-1\right)\right)$, maka dapat diperlihatkan bahwa $\varphi_{Z}(t)=\left[\varphi_{n}(t)\right]^{n}$.

\section{Keterbagian Tak Hingga Sebaran Riemann Zeta}

Misalkan didefinisikan $X=-\log n$ adalah suatu peubah acak bagi sebaran Riemann Zeta, maka fungsi kepekatan peluang dari sebaran Riemann Zeta adalah

$$
f(-\log n)=\frac{1}{\zeta(\sigma) n^{\sigma}} \quad n=1,2,3, \cdots
$$


dimana $\zeta(\sigma)$ adalah suatu fungsi Riemann Zeta.

Misalkan $X=-\log n$ adalah suatu peubah acak bagi sebaran Riemann Zeta, maka

$$
\begin{aligned}
\varphi_{X}(t) & =E\left[e^{i t(-\log n)}\right] \\
& =E\left[e^{-i t \log n}\right] \\
& =E\left(n^{-i t}\right) \\
& =\frac{\zeta(s)}{\zeta(\sigma)}
\end{aligned}
$$

merupakan fungsi karakteristik bagi sebaran Riemann Zeta.

Untuk selanjutnya, dari fungsi karakteristik sebaran Riemann Zeta yang telah didapat, akan dikonstruksi suatu persamaan yang merupakan keterbagian tak hingganya dengan menggunakan fungsi Von Mangoldt. Berikut akan diberikan definisi yang berkaitan dengan fungsi Von Mangoldt serta akan ditentukan suatu persamaan Riemann Zeta dengan menggunakan fungsi Von Mangoldt.

Definisi 3.1. [3] Fungsi Von Mangoldt $\Lambda$ didefinisikan sebagai berikut.

$$
\Lambda(n)= \begin{cases}\log p & ; n=p^{k} \quad k=0,1,2, \cdots \\ 0 & \text { selainnya }\end{cases}
$$

dimana $p$ adalah suatu bilangan prima.

Berdasarkan definisi fungsi Von Mangoldt, akan dinyatakan fungsi Riemann Zeta dalam bentuk fungsi Von Mangoldt.

Misal $p=\zeta(\sigma)$ adalah bilangan prima, maka

$$
\begin{aligned}
\log p & =\log \zeta(\sigma) \\
& =\log \prod_{p}\left(1-\frac{1}{p^{\sigma}}\right)^{-1} \\
& =-\sum_{p} \log \left(1-p^{-\sigma}\right) \\
& =\sum_{p} \sum_{m=1}^{\infty} \frac{p^{-m \sigma}}{m} \\
& =\sum_{p} \sum_{m=1}^{\infty} p^{-m \sigma} \frac{1}{m} .
\end{aligned}
$$

Perhatikan bahwa untuk $p^{-m \sigma}$ berlaku

$$
p^{-m \sigma}=\left\{\begin{array}{rr}
n^{-\sigma} & ; n=p^{m} \\
0 & \text { selainnya. }
\end{array}\right.
$$


Selanjutnya dengan menggunakan fungsi Von Mangoldt untuk $\frac{1}{m}$ diperoleh

$$
\begin{aligned}
n & =p^{m} \\
m & =\frac{\log n}{\log p} \\
m & =\frac{\log n}{\Lambda(n)} \\
\frac{1}{m} & =\frac{\Lambda(n)}{\log n} .
\end{aligned}
$$

Oleh karena itu

$$
\frac{1}{m}=\left\{\begin{array}{rr}
\frac{\Lambda(n)}{\log n} & ; n=p^{m} \\
0 & \text { selainnya }
\end{array}\right.
$$

Berdasarkan persamaan 3.2 dan 3.3 diperoleh

$$
\begin{aligned}
\log \zeta(\sigma) & =\sum_{n=2}^{\infty} \frac{\Lambda(n)}{\log n n^{\sigma}} \\
\zeta(\sigma) & =\exp \sum_{n=2}^{\infty} \frac{\Lambda(n)}{\log n n^{\sigma}} \\
\zeta(\sigma+i t) & =\exp \sum_{n=2}^{\infty} \frac{\Lambda(n)}{\log n} n^{-(\sigma+i t)} .
\end{aligned}
$$

Persamaan 3.4 adalah bentuk fungsi Riemann Zeta jika dinyatakan dalam bentuk fungsi Von Mangoldt.

Teorema 3.2. Misal $X=-\log n$ adalah suatu peubah acak bagi sebaran Riemann Zeta. Maka fungsi karakteristik dari sebaran Riemann Zeta adalah terbagi tak hingga.

Bukti. Fungsi karakteristik sebaran Riemann Zeta adalah $\varphi_{X}(t)=\frac{\zeta(\sigma+i t)}{\zeta(\sigma)}$. Misal $p=\frac{\zeta(\sigma+i t)}{\zeta(\sigma)}$. Dengan mensubstitusikan nilai $p$ ke dalam fungsi Von Mangoldt, diperoleh

$$
\begin{aligned}
\varphi_{X}(t) & =\frac{\zeta(\sigma+i t)}{\zeta(\sigma)} \\
& =\exp \left[\left(\log \left(\frac{\zeta(\sigma+i t)}{\zeta(\sigma)}\right)\right]\right. \\
& =\exp [\log (\zeta(\sigma+i t))-\log (\zeta(\sigma))] \\
& =\exp \left[\log (\zeta(\sigma))\left(\frac{\log \zeta(\sigma+i t)}{\log \zeta(\sigma)}-1\right)\right] \\
& =\exp \left[\log \zeta(\sigma)\left(\sum_{n=2}^{\infty} \frac{\Lambda(n)}{\log \zeta(\sigma) \log n n^{\sigma+i t}}-1\right)\right] \\
& =\exp \left[\log \zeta(\sigma)\left(\sum_{n=2}^{\infty} \frac{\Lambda(n)}{\log \zeta(\sigma) \log n n^{\sigma}} \exp (-i t \log n)-1\right)\right]
\end{aligned}
$$


Persamaan 3.5 merupakan fungsi karakteristik sebaran Riemann Zeta yang dinyatakan dalam fungsi Von Mangoldt. Jumlah dari bagian eksponen dapat diidentifikasi sebagai suatu fungsi karakteristik dengan mendefinisikan $Y=-\log n$ sebagai peubah acak, dengan penjabaran sebagai berikut

$$
\begin{aligned}
P(Y=-\log n) & =\frac{\Lambda(n)}{\log \zeta(\sigma) \log n n^{\sigma}} \\
\varphi_{Y}(t) & =E\left[e^{i t Y}\right] \\
& =E\left[e^{i t(-\log n)}\right] \\
& =E\left[n^{-i t}\right] \\
& =\sum_{n=2}^{\infty} n^{-i t} \frac{\Lambda(n)}{\log \zeta(\sigma) \log n n^{\sigma}} .
\end{aligned}
$$

Pilih $\mu=\log \zeta(\sigma)$, maka $\varphi_{X}(t)$ dapat dijadikan sebagai berikut

$$
\varphi_{X}(t)=\exp \left(\mu\left(\varphi_{Y}(t)-1\right)\right) .
$$

Berdasarkan Teorema 3.2 dapat ditarik kesimpulan bahwa sebaran Riemann Zeta adalah suatu sebaran terbagi tak hingga.

\section{Kesimpulan}

Sebaran Riemann Zeta didefinisikan sebagai berikut

$$
f(-\log n)=\frac{1}{\zeta(\sigma) n^{\sigma}} \quad ; \sigma>1,
$$

dimana $\varsigma(\sigma)$ adalah fungsi Riemann Zeta yang didefinisikan sebagai

$$
\zeta(s)=\sum_{n=1}^{\infty} \frac{1}{n^{s}} \quad ; s=\sigma+i t, \sigma>1, t \in R,
$$

Fungsi karakteristik dari sebaran Riemann Zeta adalah

$$
\varphi(t)=\frac{\zeta(\sigma+i t)}{\zeta(\sigma)}
$$

Fungsi karakteristik ini dapat pula dinyatakan dalam bentuk

$$
\varphi_{X}(t)=\exp \left[\log \zeta(\sigma)\left(\sum_{n=2}^{\infty} \frac{\Lambda(n)}{\log \zeta(\sigma) \log n n^{\sigma}} \exp (-i t \log n)-1\right)\right],
$$

dimana $\Lambda(n)$ adalah fungsi Von Mangoldt. Bentuk ini merupakan suatu keterbagian tak hingga sebaran Riemann Zeta.

\section{Ucapan Terima kasih}

Penulis mengucapkan terima kasih kepada Bapak Dr. Dodi Devianto, Ibu Hazmira Yozza, M.Si, Bapak Dr. Admi Nazra, Bapak Yudiantri Asdi, M.Sc dan Bapak Prof. Dr. Syafrizal, Sy yang telah memberikan masukan dan saran dalam penyempurnaan penulisan artikel ini. 


\section{Daftar Pustaka}

[1] Chung, K. L . 2001. A Course In Probabillity Theory Third Edition. San Diego: Academy Press.

[2] Gnedenko, B. V and A.N Kolmogorov. 1968. Limit distributions For Sums Of Independent Random variables. Ontario: Wesley Publishing Company.

[3] Gut, Allan. 2005. Some Remarks On The Riemann Zeta Distributions. UUDM Report. Vol.6

[4] Gwo Dong Lin and Chin-Yuan Hu. 2001. The Riemann Zeta Distribution. Bernoulli. Vol. 7(5). pp. $817-828$.

[5] Karatsuka, A. A and S.M Varonin. 1992. The Riemann Zeta Function. Berlin: Walter De Gluyter.

[6] Lukacs, E. 1992. Characteristic Function Second Edition. London: Griffin.

[7] Patterson, S. J. 1998. An Introduction To The Theory Of Riemann Zeta Function. Cambridge: University Press.

[8] Tucker, H.G. 1967. Probability and Mathematical Statistics. London: Academic Press. 